\title{
Disruptive Innovation Within the Legal Services Ecosystem
}

Donald G. Billings, DBA

Sidley Austin LLP, Chicago, Illinois, United States

(iD https://orcid.org/0000-0002-2305-0399

Douglas G. Campbell, $\mathrm{PhD}$

Walden University, Minneapolis, Minnesota, United States

(iD) https://orcid.org/0000-0002-3989-1571

Contact: $\underline{\text { dbillings@sidley.com }}$

\begin{abstract}
Many law firms have done little to address the opportunities and threats presented by potentially disruptive technology (DT), such as artificial intelligence and machine learning. The purpose of this multiple-case study was to explore strategies that some law firm leaders use to address the potentially detrimental influences of DT on their organizations. The systems approach to management was employed as the conceptual framework. Data were collected from six participants at two international law firms with offices in California, using semistructured interviews and organizational artifacts. Data were analyzed using inductive and deductive coding and thematic analysis, resulting in four themes: (a) recognizing the legal ecosystem and legal firms are open systems, but organizational subsystems often function as semiclosed systems; (b) acknowledging that although DT represents the most significant potential challenge in the near future, the immediate challenge is improving technology, which requires organizational adjustments; (c) recognizing the need for firms to invest more heavily in innovation generation activities; and (d) realizing the need for increased utilization of augmenting technologies, such as artificial intelligence or machine learning, to streamline nonadvisory outputs. The findings of this study suggest that, while disruptive innovation may pose a moderate threat, there are also significant advantages to adopting disruptive innovation as a formal aspect of organizational strategy. The results of this study may contribute to social change by outlining ways in which firms can lower costs to clients while increasing access to legal services for those in underserved communities.
\end{abstract}

Keywords: systems; artificial intelligence; machine learning; disruptive innovation; law firm; legal system

Date Submitted: August 24, 2019 | Date Published: May 212020

\section{Recommended Citation}

Billings, D. G. \& Campbell, D. G. (2020). Disruptive innovation within the legal services ecosystem. International Journal of Applied Management and Technology, 19, 26-39. https://doi.org/10.5590/IJMAT.2020.19.1.03 
Billings \& Campbell, 2020

\section{Introduction}

\section{Background of the Problem}

In 2011, academics, researchers, and notable members of the popular press first described the potential for disruption within the legal services ecosystem, driven by disruptive technologies (DTs), such as artificial intelligence (AI) and machine learning (ML; Simpson, 2016). Despite widespread consensus of legal industry leaders regarding the need to address the increased competitive threats, including the evolution of DTs, less than half of those participating in an industry study reported making any significant adjustments to their traditional business models (Clay \& Seeger, 2014).

Although Christensen and colleagues (2015) formalized the concept of disruptive innovation (DI) as a business theory more than 2 decades ago, it was only as recently as 2015 that law firm leaders in the United States began to recognize the role DI may play within the broader legal services ecosystem (Brescia, 2015). As an open system, boundaries within the legal services ecosystem are both dynamic and porous, allowing for the exchange or sharing of information and feedback (Brescia, 2015). Most often, external influences, such as the political climate, economic conditions, or even technological disruptions, remain outside the control of the organization and may include (LoPucki, 1996). Of leaders within the legal services ecosystem, only a small number have actively developed strategies aimed at addressing the potential effect that DTs may have on existing business models (Dolin \& Buley, 2015). This lack of proactivity continues despite a growing consensus among scholars that technological disruption of the legal industry is inevitable (Katz, 2014). According to Christensen et al. (2015), DI is a transformational process by which organizations are innovating at the lower end of the market, typically in niche areas neglected by established incumbents, and transforming existing industries dominated by high cost and complex products or services. Such innovations tend to focus on features such as ease of use, costs, and convenience. Over time, the broader adoption of the product or service could completely redefine an industry (Christensen et al., 2015).

Between 2006 and 2016, corporations reduced spending on outside legal services (Barton, 2014). This trend corresponded to increased client-driven demand for greater efficiency and improved metrics-driven accountability throughout the legal industry (Butler \& Kobayashi, 2014; Moppett, 2013; Ribstein, 2012; Simpson, 2016). These shifts in demand for improved efficiency helped bolster the growth of new market entrants, including entrepreneurs and venture-backed legal technology companies offering early iterations of $\mathrm{AI}$ and ML technologies designed to automate functions previously performed by lawyers (Barry, 2012; McGinnis \& Pearce, 2014).

\section{Problem Statement}

Following the economic downturn of 2008, law firm leaders in the United States experienced increased external pressure to improve operational efficiency through technology adoption (Giroud \& Mueller, 2017). Between 2008 and 2015, the failure of some law firm leaders to implement strategies to improve efficiency and adopt new technologies contributed to the dissolution of more than 25 U.S.-based international law firms, some of which had been in business since the mid-180os (Sheppard, 2015). Indication are that some law firm leaders in the United States lack strategies to address the potentially negative systems effects of DTs, such as $\mathrm{AI}$ and ML, on their organizations.

\section{Purpose and Research Question}

The purpose of this qualitative, descriptive multiple-case study was to explore strategies that some law firm leaders in the United States use to address the potentially detrimental influences of DTs, such as AI and ML, on their organizations. The overarching research question was this: What strategies do law firm leaders in the United States use to address the potentially detrimental influences of DTs, such as AI and ML? 


\section{Conceptual Framework}

The conceptual framework for this research was the systems approach to management, a framework designed to guide practitioners to optimize decision making within an organization (Laszlo, 1975). According to Katz and Kahn (1966), when focused on open or closed organizational systems, the critical analysis constructs underlying the systems approach to management are (a) external influences from stakeholders such as customers, competitors, government entities, and suppliers; (b) inputs from the stakeholders and outputs from the organization to the stakeholders; and (c) internal processes that apply the inputs and create outputs. LoPucki (1996) proposed applying system analysis to address challenges within the legal ecosystem through a framework the author described as the systems approach to law. LoPucki suggested that the complexity of the practice of law could be better understood by viewing the profession as a broader ecosystem through the lens of systems analysis.

Understanding how interconnectedness and external influences affect organizational systems allows firms to more effectively address any externally driven challenges that might otherwise disrupt existing business models (Nobles \& Schiff, 2013). As applied to this study, the core concepts of systems approach to management allowed participants to adequately explore and express their perceptions and strategies related to creating goals to address potential disruption from technologies, such as AI and ML.

\section{Method}

\section{Population and Sampling}

The sample population for the study consisted of six key leaders at two large U.S. law firms, who were responsible for the development, implementation, and strategic management of technology related strategies. We employed purposeful, snowballing-based sampling as a mechanism for both identifying and recruiting the participants. We determined an appropriate sample size for this study by first identifying the known number of potential participants perceived as thought leaders by their peers within the legal technology field and who meet the experience criteria related to developing, implementing, and managing automation solutions in the legal industry.

\section{Data Collection}

The data collection process involved face-to-face, semistructured interviews through the use of open-ended questions and reviews of organizational documents, including memos, marketing material, research material, and other archival documents that participants provided.

\section{Data Analysis}

Data analysis was done using a mix of inductive and deductive coding, and using a computer research application (Dedoose, 2015). As recommended by Bernard (2013), we used coding as the primary data analysis technique to derive the interpretative aspect of the analysis and capture both the textural and structural meanings within a systems science construct. This was a disciplined approach to reduction and imaginative variation that enabled me to evaluate my biases and assumptions continually in a way that better ensured my openness to new insights or ideas. As part of the analysis process, we correlated the key themes that emerged from the interview process with both the academic literature and the conceptual framework (Fusch \& Ness, 2015; Yin, 2015). The final step involved a level of data interpretation that helped me identify any patterns or differences among the data. 


\section{Results}

Based on the data analysis, four key themes emerged: (a) recognizing legal ecosystems and legal firms are, at the macrolevel, open systems, but organizational subsystems often function as semiclosed systems; (b) acknowledging that, although DT represents the most significant potential challenge in the near future, the immediate challenge is in incrementally improving technology that requires organizational adjustments; (c) recognizing the need for firms to invest more heavily in innovation generation activities; and (d) realizing the need for increased utilization of augmenting technologies, such as AI or ML, to streamline nonadvisory outputs.

\section{Theme 1: Law as an Open System}

Responses indicated that study participants agreed that the legal ecosystem as a whole is open, and as such, subject to external influences, such as technology vendors, clients, and government agencies. One participant described the inputs from clients and government agencies that drive a significant portion of the firm's strategy, but $67 \%$ of the participants thought that most of their organization's subsystems were not significantly or directly affected by those external forces. Collected surveys and deployment documentation provided by one participant pointed to the external influences of clients as a driving force behind DT adoption, a theme echoed by the study participants.

All six participants described experiencing at least some challenges related to both flow and synergy at the departmental or subsystem level, where departments or functions and personnel often operate in isolation, limiting the exchange of ideas and resources. Participants lamented a lack of synergy among departments and firms and described a lack of willingness within law firms to move past local system boundaries and create synergies across departments in a way that might improve adoption and idea generation within the organization. One participant described environments in which adoption of DTs, such as AI and ML, were often siloed within the subsystem, such as IT, slowing adoption across other levels of the organization. Figure 1 illustrates the application of the systems theory of management to the legal ecosystem, allowing practitioners to address the complexities of the legal ecosystem, including evaluating external threats and opportunities originating outside traditional organizational boundaries (LoPucki, 1996).

Participants described solutions to these challenges, including improving cross-boundary activity for both developing and deploying DT solutions and leveraging tools beyond their intended purposes (e.g., using ML tools designed to streamline eDiscovery review for tasks with due diligence within transactional practices). Another participant suggested exploring synergies from outside the legal system, such as potentially leveraging photo recognition AI tools from tech companies, such as Google, to solve problems related to finding handwritten documents within litigation review databases.

The participants' responses contributing to Theme 1 are aligned with the system literature as well as the conceptual framework. Susskind and Susskind (2016) taught that the legal ecosystem exists as a subsystem within a larger system of the professions, with each subsystem influencing one another. Susskind (2013) went on to claim that, if removed from the broader system, these mechanical functions could not operate as independent systems because they are dependent upon the organization as a whole. 


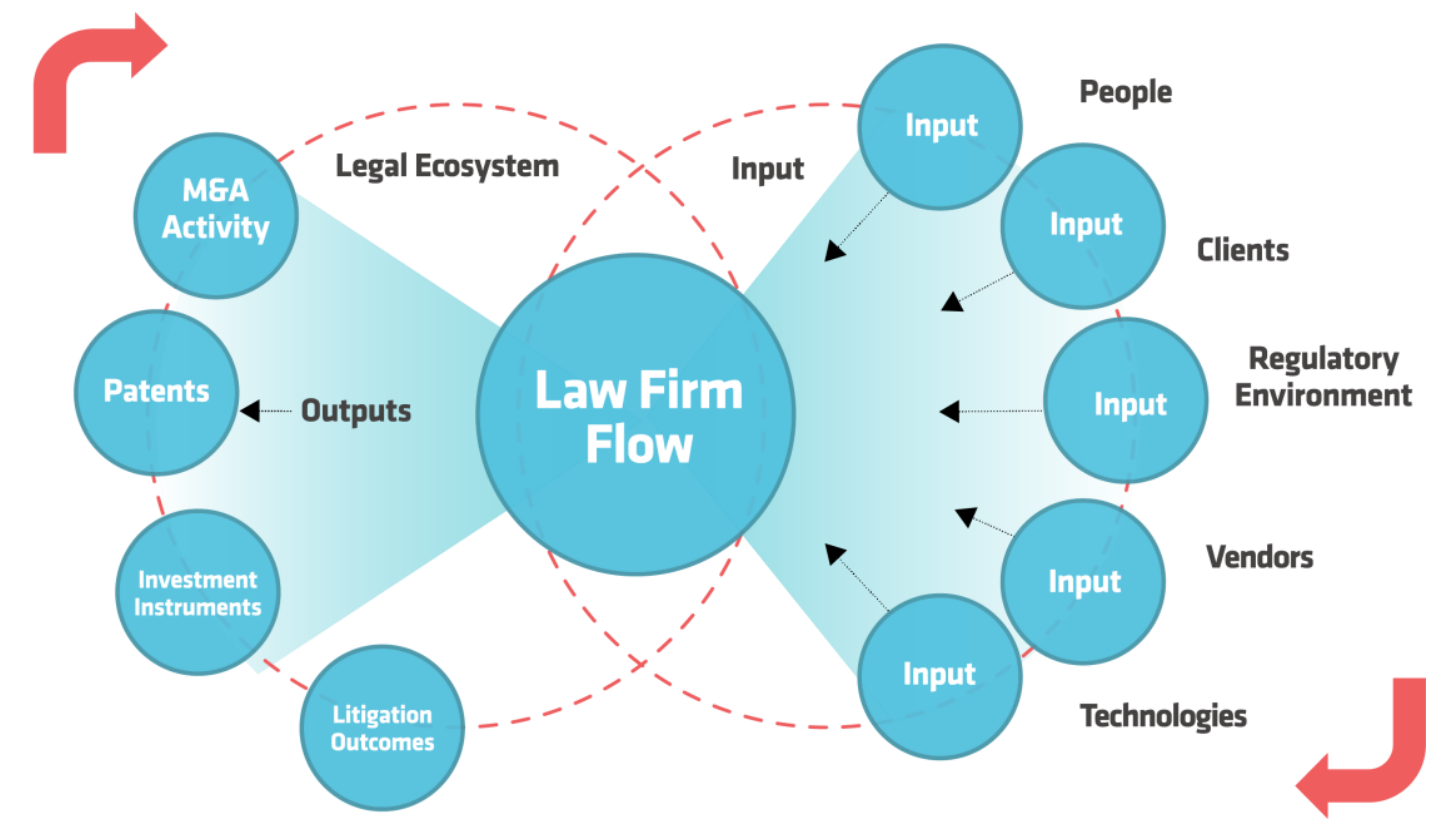

Figure 1. Original Rendering Applying the Systems Theory of Management to the Legal Ecosystem. Adapted from LoPucki (1996). M\&A = merger and acquisition.

According to Horst et al. (2015), the systems theory of management dictates that organizations exist in an environment, surrounded by significant forces that determine the progression of activities within the company. As such, organizations might choose to operate in either an open or closed system structure. In the open structure, the external environment affects organizations, with interactions occurring through the exchange of information, input, and output to the ecosystem. Horst et al. (2015) went on to claim that such systems are divided by a permeable boundary between the firm and the environment through social, political, and economic systems. The influences described included company personnel, marketing channels, and the inputs and other materials involved (Horst et al., 2015). The study participants agreed that the legal ecosystem as a whole is open, and as such, subject to outside influences from external organizations, such as vendors, clients, and government agencies. In addition, participants illustrated the ways in which external influences combine with cross-boundary activity influences in internal strategy related to potential DTs, such as AI and ML. Table 1 illustrates the frequency with which participants mentioned the law as an open system.

Table 1. Law as an Open System (Frequency)

\begin{tabular}{|c|c|c|}
\hline Participant & Interview questions & Number of references \\
\hline Boo1 & $2,5,6$ & 10 \\
\hline Boo2 & $2,4,5,6$ & 12 \\
\hline Boo3 & $2,4,6$ & 7 \\
\hline Loo1 & $2,4,5,6$ & 8 \\
\hline Loo2 & $1,2,5,6$ & 6 \\
\hline Loo3 & $2,4,5,6$ & 9 \\
\hline
\end{tabular}

Note. Illustrates the frequency of participants mentioning the law as an open system. B = Case $1 ; \mathrm{L}=$ Case 2 . 


\section{Theme 2: Differentiation Between Disruption and Incremental Improvement}

Of the participants, $83 \%$ agreed that current technologies, while innovative, are merely augmenting the work of lawyers and professional staff in large firms. For example, one participant pointed out that displacement of personnel involved in these now commoditized tasks has led to opportunities elsewhere in the organization, such as the creation of new positions like technologists and data scientists, who work hand in hand with the firm's lawyers to improve the overall quality of the service while simultaneously driving down costs.

Participants agreed that changes in traditional models were happening at the lower end of the market and are augmenting rather than replacing the work performed by lawyers or paralegals. They expressed at least some skepticism over how deeply their competitors were innovating through the deployment of DTs. Participants cited the marketing hyperbolae often used to describe technologies or trends in industry seminars and workshops, and described a disconnect within the ecosystem, where mere incremental innovations, process improvements, or reimagined workflows are often touted as disruptive. The disconnect between the marketing hyperbole and true disruption is supported by the archival materials. Figure 2 contains an excerpt from a 2018 industry report by Thompson Hine (2017), revealing that, from the perception of clients, only 4\% of their external firms have engaged in significant innovation, with $45 \%$ citing innovation as modest.

\section{Over the past three years, how much innovation have you seen from law firms?}

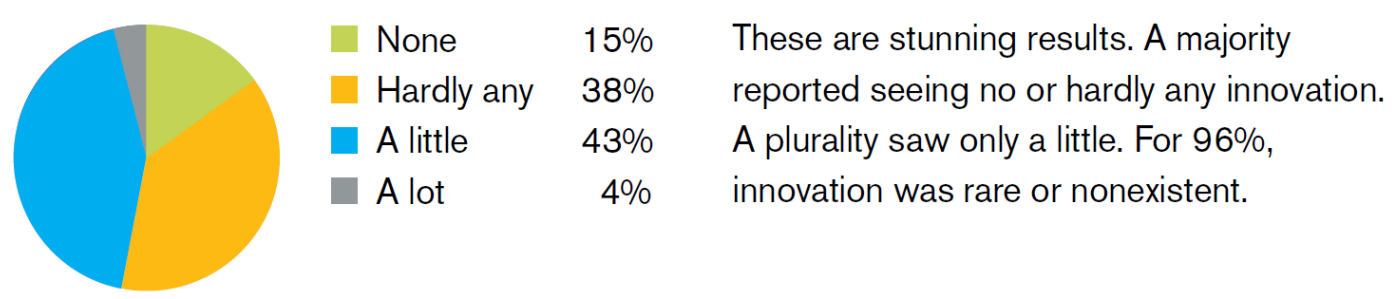

\footnotetext{
Figure 2. Industry Report: Closing the Innovation Gap. A direct excerpt from an industry report reviewed by participants in case two as part of an internal strategic review. The authors of the report point to a disconnect between marketing hyperbole and true innovation within the legal ecosystem (copyright 2017 by Thompson Hine. Reprinted with permission).
}

The archival document cited in Figure 3, a 2017 industry report from Weil (2017), purports to show a significant disconnect between what firms are describing as DI and the perceptions of their corporate clients. Most notably, based on the survey of corporate legal services clients, there is a perception that only $2 \%$ of firms are engaged in any real innovation. Weil found that 94 of the respondents thought that improving efficiency would continue to be a more permanent trend, but only $49 \%$ have made the changes required to improve the efficiency of legal service delivery. Weil noted that the two efficiency techniques of knowledge management had not yet born out the success and credible results that firms had hoped for. 


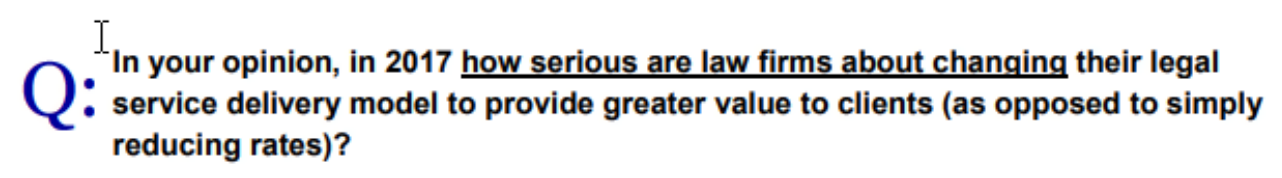
reducing rates)?

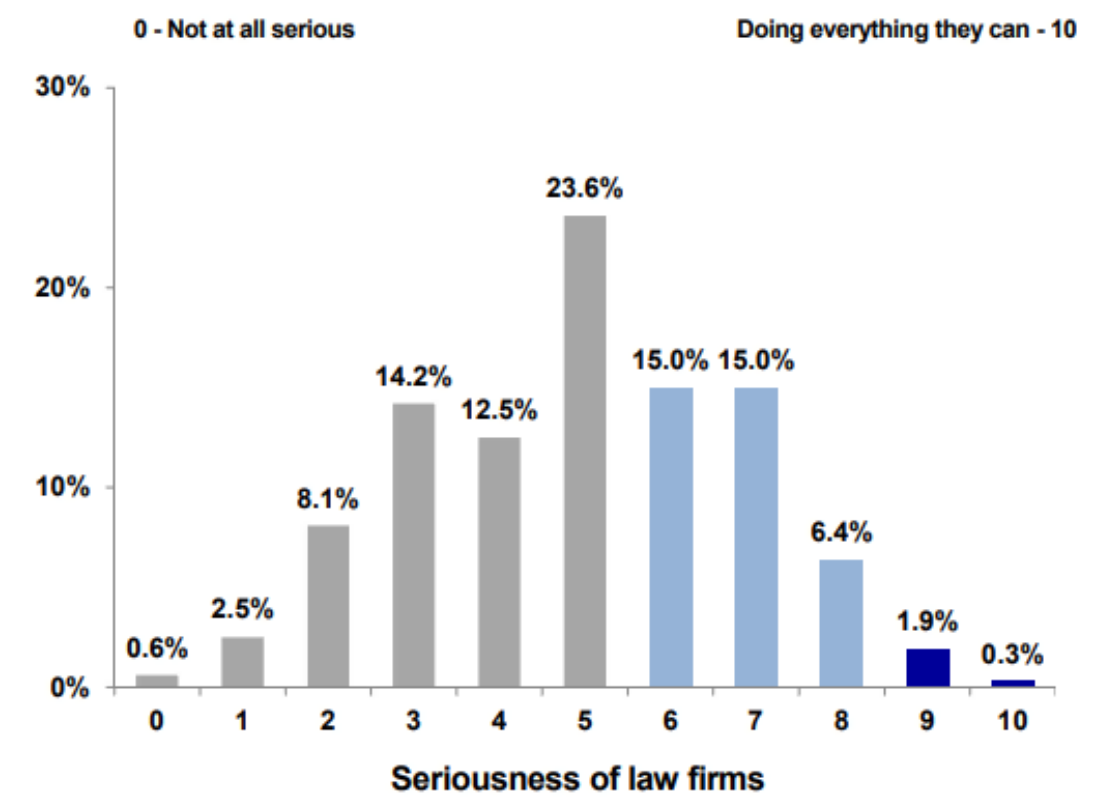

\begin{tabular}{|c|c|c|c|c|c|c|c|c|c|c|c|}
\cline { 2 - 11 } \multicolumn{1}{c|}{} & \multicolumn{4}{c|}{ LOW } & \multicolumn{3}{c|}{ MODERATE } & \multicolumn{2}{c|}{ HIGH } \\
\hline RATING & 0 & 1 & 2 & 3 & 4 & 5 & 6 & 7 & 8 & 9 & 10 \\
\hline RESPONSE & \multicolumn{4}{c|}{$61.5 \%$} & \multicolumn{3}{c|}{$36.4 \%$} & $2.2 \%$ \\
\hline
\end{tabular}

Median rating: 5

Figure 3. Industry Report: 2017 Law Firms in Transition Survey. A direct excerpt from an industry report reviewed by participants in case two as part of an internal strategic review. The authors of the report point to the disconnect between marketing hyperbole and true innovation within the legal ecosystem (copyright 2017 Law Firms in Transition Survey, Altman Weil, Inc., www.altmanweil.com/LFiT2017. Reprinted with permission. All rights reserved).

According to Weil, these techniques seek to change the established behavior of lawyers that has become fundamental and are therefore difficult to alter from a culture change perspective. This overarching theme that emerged from the artifacts aligned with the sentiments of the interviewees with regard to technology adoption serving to augment lawyer and paralegal activity as opposed to serving as a catalyst for disruption. Moreover, the focus on externally driving lawyer behavior to improve outcomes aligns directly with the conceptual framework. Among the tenants of the system theory of management are the concepts of inputs, outputs, and flow, often driven by influence origination outside of organization boundaries. Both the artifacts 
provided and interview responses from all six participants pointed to external influences on inputs, flows, and outputs as well as the strategies employed to address those influences.

From a strategic planning perspective, participants described a number of areas where DT was potentially deployed to improve the overall workflows in areas such as contract preparation, transactional closings, eDiscovery, and workflow automation or case management. Participants pointed to specific solutions, such as document automation tools, that augment work performed by legal professionals through the use of logicbased systems designed to leverage preexisting data to generate entirely new documents. Participants provided archival documents in the form of internal product announcements, which documented the internal release of these products and described them as augmenting and not displacing existing lawyers and professional staff. Although the innovations cited by participants can be described as more incremental in nature, the potential for improving flow while simultaneously increasing outputs remains an essential aspect of innovations strategy.

Five participants pointed to areas where competitive advantage might be achieved through either improved access to advisory services or by creating new practice areas. Two participants provided examples of areas where entire practices might be built through the creation of advanced advisory services in areas such as intellectual property, privacy law, and compliance. One participant discussed the potential for eliminating lower-level work, allowing senior lawyers to reduce the time spent on mundane tasks, ultimately freeing them up to work on higher-level projects. Table 2 illustrates the frequency at which participants mentioned the law as a system.

Table 2. Disruption Versus Incremental Improvement (Frequency)

\begin{tabular}{|c|c|c|}
\hline Participant & Interview questions & Number of references \\
\hline Boo1 & $1,3,4$ & 32 \\
\hline Boo2 & $1,3,4,6,7$ & 23 \\
\hline Boo3 & $1,2,4,6$ & 22 \\
\hline Loo1 & $2,4,5,6,7,8$ & 30 \\
\hline Loo2 & $1,4,6,7,8$ & 19 \\
\hline Loo3 & $2,4,5,6$ & 34 \\
\hline
\end{tabular}

Note. Table 2 reflects the frequency at which participants mentioned incremental innovation. B = Case 1; L = Case 2.

\section{Theme 3: Innovation Generation}

In discussing DT strategies and challenges experienced within their organizations, participants described the need to formally drive internal innovation strategy through external partnerships, dedicated internal departments, or through wholly owned subsidiaries focused on the development of innovative products. Participants cited formal innovation generation activities, including an approach that involved a significant focus on incorporating innovation strategy into new practice areas and less on technology solutions. Participants also cited innovation practices among peer firms.

Participants described several innovation development strategies, including innovation incubators within the legal sector and partnerships among law firms and external technology developers, specifically in areas such as eDiscovery. Participants from both cases further extolled the potential benefits of deploying DIs as a means of decreasing time spent on low value activities, freeing lawyers and professional staff to focus on increasing revenue-related outputs through improved advisory activity.

Participants described an environment in which innovation was taking place, but often within siloed departments. They recommended breaking down boundaries in a way that better ensures that organizational 
subject matter experts would have more input into the design and functionality of AI and ML tools. They also recommended improving cross-departmental pollination of technology, including ensuring disparate departments continue to share any organizational learning around DT with members of other departments. Two participants in group two suggested exposing a broader scope of personnel in firm innovation generation activity. Of the methods deployed to improve innovation activity, strategic partnerships with vendors or others outside the traditional law firm environment were cited as improving strategic positioning. This improved positioning was most apparent in external recognition of the firm in the form of awards and recognition within the legal press. One participant described the benefits of working with technology partners outside of the legal marketplace because they are often better capitalized than their legal-only peers, and many of the tools they create for a more general audience can be customized for use within the legal ecosystem.

According to Simon and colleagues (2018), advanced technologies, such as AI and ML, are becoming more affordable and well on their way toward automating at least some of the work currently performed by lawyers and professional staff. Simon et al. (2018) pointed to other markets in which assembly-line workers, stockbrokers, and travel agents have seen their industries universally transformed. Moreover, combined advances in the availability of big data and natural language processing have revolutionized the predictive capabilities of many decision algorithms, facilitating such advancements as autonomous vehicles. Simon et al. (2018) described an ever-growing entanglement between technology and a new era of legal services, claiming that practitioners in the near future will rely on algorithms to automate time-consuming tasks typically assigned to junior lawyers or professional staff. Table 3 has the frequency with which participants described innovation generation, supporting the emergence of law as an open system as a theme.

Table 3. Innovation Generation Activities (Frequency)

\begin{tabular}{|c|c|c|}
\hline Participant & Interview questions & Number of references \\
\hline Boo1 & $1,7,8$ & 15 \\
\hline Boo2 & $1,7,8,9$ & 13 \\
\hline Boo3 & $1,8,9$ & 13 \\
\hline Loo1 & $1,7,8,9$ & 11 \\
\hline Loo2 & $5,6,7$ & 17 \\
\hline Loo3 & $1,6,7$ & 11 \\
\hline
\end{tabular}

Note. Table 3 reflects the frequency at which participants described innovation generation activities as a theme. $\mathrm{B}=\mathrm{Case}$ 1; $\mathrm{L}=$ Case 2 .

\section{Theme 4: Application of AI or ML to Streamline Nonadvisory Outputs}

Despite the broad focus on the potential threats of DI on the legal ecosystem, law firm leaders appear to be focusing their core innovation strategies in areas such as process improvement, automation, and practice augmentation. When asked about strategies to address DT, all six participants cited the deployment of practice augmentation tools, such as those used for research, document assembly, eDiscovery, and diligence. One participant described how business process automation software automates routine sub processes in a manner that allows the practitioner and automated system to operate as a seamless unit. These systems are not intended to replace human output, but instead automate specific routine tasks at various stages in the process, improving quality and standardizing flow along the way.

Another participant described several augmenting technologies that have been deployed within the organization over the previous 2 years, including automation tools for transactional closings, legal research, contract drafting, eDiscovery analytics, and predictive technologies. To support these claims, this participant provided organizational artifacts and multiple internal memoranda announcing the deployment of tools, such 
as Doxly, Kira, Brainspace, and Kara AI. Another participant expanded on this theme, citing augmentation and incremental innovation as a core strategy for addressing disruption, and pointed to improved synergies among lawyers, technologists, and tools as providing a significant competitive advantage.

Participants described augmentation as essential in their organizations, with 66\% (i.e., four) citing incremental innovation as a core element of long-term strategy. One participant acknowledged that a core challenge to addressing potential disruption was a lack of clarity within the ecosystem around the definition of disruption. Table 4 has the frequency with which participants described streamlining nonadvisory outputs as a theme.

Table 4. Streamlining Nonadvisory Outputs (Frequency)

\begin{tabular}{|c|c|c|}
\hline Participant & Interview questions & Number of references \\
\hline Boo1 & $3,7,8$ & 6 \\
\hline Boo2 & $1,3,7,8$ & 12 \\
\hline Boo3 & 7 & 9 \\
\hline Loo1 & $3,7,8$ & 11 \\
\hline Loo2 & 7,8 & 9 \\
\hline Loo3 & $3,7,8$ & 5 \\
\hline
\end{tabular}

Note. Table 4 reflects the frequency at which participants described streamlining nonadvisory outputs as a theme. $\mathrm{B}=$ Case $1 ; \mathrm{L}=$ Case 2 .

\section{Discussion}

\section{Applications to Professional Practice}

Leaders actively seeking to implement DT strategies in their organizations require current information related to the potential state of disruption within the legal ecosystem due to the evolving nature of the technologies involved. The knowledge gleaned from this research could enable law firm leaders to ensure appropriate processes and strategies are in place to address potential DT. In addition, that information could allow law firm leaders to prepare for previously unanticipated disruption events. Based on the present findings, the immediate challenge for law firm leaders lies in the ability to leverage incremental innovations improving technology that requires organizational adjustments. Law firm leaders could potentially adjust their innovation strategies to include more sustaining innovations designed to augment the work performed by lawyers and professional staff in an effort to benefit from improving already existing processes. This includes the potential deployment of incremental and process innovations with tools such as business process automation software, automated decision trees, and other forms of augmenting technologies.

Remus and Levy (2015) explored the current capabilities of ML and AI technologies and concluded that true disruption to traditional legal models is unlikely, due in part to the nuanced and normative nature of the practice of law. They argue that changes produced by these technologies will be more evolutionary, enhancing rather than displacing the work performed by most lawyers and paralegals. In all, 83\% of the study participants concurred with Remus and Levy. Participants from both cases cited specifically the importance of improving processes at the lower end of the value chain, such as document review, a practice that once involved hiring dozens of associates to review hundreds of boxes of documents by hand. While arguably displacing the workers once performing these tasks, this evolution from traditional linear review to a humanmachine hybrid approach may lead to opportunities elsewhere in the organization. Specifically, the participants described witnessing an increase in the creation of new positions within the organization, such as professional technologists, data scientists, and even chief innovation officers working hand in hand with a 
firm's lawyers to improve the overall quality of the service while simultaneously driving down the costs of lower value outputs.

The results from this study might provide additional material for law firm leaders to employ in championing strategies aimed at addressing DT. Petrick and Martinelli (2012) noted that driving DI requires companies to possess strategies to better forecast nonobvious problems that might require solutions at a future point in time and laid out a strategy that included monitoring external environments through a process known as road mapping. This road mapping allows organizations to anticipate and plan for innovation. The findings of the study may contribute to broader industry and educational research related to formal DT strategies. Moreover, the findings suggest a need to view strategies related to potential DT within the context of the broader legal ecosystem.

\section{Conclusions}

Based on the research findings, we recommend the following actions: To better forecast and defend against any potential threats from DT, law firm leaders should adopt a systems approach strategy that effectively integrates all the components (e.g., people, processes, and systems). Leaders can map both existing internal resources as well as potential external influences in the chain to formally identify threats and opportunities within the legal ecosystem. Law firm leaders can also learn from individuals responsible for managing and implementing, and managing these people processes, and systems. Further, law firm leaders should encourage partners and professional staff to remain aware of potential threats from DT, rather than just highly skilled technical staff who are often segregated from the legal teams in organizational silos. Integrating professional staff with legal teams could potentially speed organizational learning related to any potential threats or opportunities. Several participants noted that proactively evaluating and exploring potentially disruptive technologies can provide an opportunity for law firm leaders and their staff to evaluate, explore, and exploit technologies to enhance competitive advantage and guard against external disruption threats.

Law firm leaders should also champion an organizational culture that fosters innovative thinking across the firm, encourages experimentation, and reduces the stigma of failure. Viewing internal strategic projects as venture investments in which a percentage is expected to fail could lead to more open collaboration and increased innovation activity over all. By developing policies that align with the goal of exploring and selectively deploying disruptive technologies within their organizations, firm leaders might develop further strategies to minimize external threats from these technologies. As part of this systems analysis, law firm leaders should dedicate resources to measuring and defining disruption within the ecosystem in a way that differentiates truly disruptive technologies from the marketing hyperbole.

Law firm leaders should consider strategic partnerships to fill any gaps in innovation strategy that might otherwise be outside the core expertise of the organization. Doing so can allow firms to discover novel ways of addressing their legal technology challenges. Moreover, such partnerships might allow firms to apply already existing technology designed for other sectors to challenges facing the legal profession in ways not originally anticipated by the developer. By leveraging existing relationships with technology vendors or consultants, firms might improve time to market for new innovations.

Finally, law firm leaders should strategize to sustain innovations designed to augment the work performed by lawyers and professional staff. Firms can benefit from improving already existing processes, including the potential deployment of incremental and process innovations with tools, such as business process automation software, automated decision trees, and other forms of augmenting technologies.

These recommendations should be considered in the context of the study's limitations. This study utilized a multiple-case design with a small sample size consisting of two cases studies with two large law firms with a presence in California. Future researchers studying DT might consider employing a different research design, 
such as the phenomenological design, to explore perceptions and experiences across a larger sample size that includes smaller firms and other regions of the United States. Future researchers should also examine topics related to emerging technologies and developing roles in law firms, such as the rise of the chief innovation officer, or technological innovations such as cryptocurrency and blockchain technologies. Other areas of potential disruption to the legal ecosystem should also be examined, such as the perceived potential threats presented by large accounting firms seeking to expand their business to include bundled legal services or nonlawyer encroachment into this space by startups, such as Legalzoom and Rocket Lawyer.

In addition, quantitative researchers might examine the number of DT programs or implementation across a broader demographic in an effort to calculate deployments and adoption across the entire industry. Thematically, the research findings demonstrate a need for law firm leaders to proactively drive their organizations to explore the threats and benefits of various disruptive technologies within their firms. Researchers could expand on my research findings by examining the effects of potentially DIs across various practice areas and organization types.

\section{Limitations of this Research}

The selection of geographically dispersed participants resulted in an inability to visit all the participants in a live environment, which could have resulted in deeper observational and descriptive notes. However, scholars, including Hamilton (2014), Hillman and colleagues (2015), and Janghorban and colleagues (2014), claimed that researchers might overcome challenges with geographically dispersed participants through the use of Skype or other video conferencing technology, such as was done in this research.

\section{Final Thoughts}

Although the themes that emerged from this research suggest that DI may pose a moderate threat, there are also advantages to adopting DI as a formal aspect of organizational strategy. There is a need for legal technology leaders to work toward improving internal synergies by breaking down system boundaries at the firm and sub department level. There is also a need for law firm leaders to explore improving flow by integrating technologies such as $\mathrm{AI}$ and ML as a means of augmenting internal operations and streamline nonadvisory outputs. Finally, law firm leaders may need to dedicate internal resources to developing crossboundary partnerships and internal exploratory groups to focus efforts on either developing or better leveraging potentially DT such as AI and ML in their organizations.

\section{References}

Barry, N. (2012). Man versus machine review: The showdown between hordes of discovery lawyers and a computer-utilizing predictive-coding technology. Vanderbilt Journal of Entertainment \& Technology Law, 15, 343.

Barton, B. H. (2014). The lawyer's monopoly-what goes and what stays. Fordham Law Review, 82, 3067.

Bernard, H. R. (2013). Social research methods: Qualitative and quantitative approaches (2nd ed.). Sage.

Brescia, R. H. (2015). What we know and need to know about disruptive innovation. South Carolina Law Review, 67, 203.

Butler, H. N., \& Kobayashi, B. H. (2014). Unlocking the law: Building on the work of Larry E. Ribstein. International Review of Law and Economics, 38, 2-4. https://doi.org/10.1016/j.irle.2013.11.003

Christensen, C., Raynor, M., \& McDonald, R. (2015). What is disruptive innovation? Harvard Business Review, 93(12), 44-53.

Clay, T., \& Seeger, E. (2014). Law firms in transition 2014: An Altman Weil flash survey. Altman Weil. 
Dedoose (Version 4.5) [Computer software]. (2015). http://www.dedoose.com

Dolin, R. A., \& Buley, T. J. (2015). Adaptive innovation: innovator's dilemma in big law (SSRN Scholarly Paper No. ID 2593621). Social Science Research Network. http://papers.ssrn.com/abstract=2593621

Fusch, P. I., \& Ness, L. R. (2015). Are we there yet? Data saturation in qualitative research. The Qualitative Report, 20, 1408-1416.

Giroud, X., \& Mueller, H. (2017). Firm leverage, consumer demand, and employment losses during the great recession. The Quarterly Journal of Economics, 132, 271-316. https://doi.org/10.1093/qje/qjw035

Hamilton, R. J. (2014). Using Skype to conduct interviews for psychosocial research. Computers Informatics Nursing, 32(8), 353-358.

Hillman, S., Neustaedter, C., Pang, C., Forghani, A., Oduor, E., Judge, T. K., Massimi, M., \& Greenberg, S. (2015). Sharing domestic life through long-term video connections. ACM Transactions on ComputerHuman Interaction, 22(1), 3. https://doi.org/10.1145/2696869

Horst, D. J., Broday, E. E., Bondarik, R., \& de Paula Xavier, A. A. (2015). Open or closed? Macroergonomics approaching socio-technical systems productivity: an overview of the conceptual framework. Social and Basic Sciences Research Review, 3(2), 98-115.

Janghorban, R., Roudsari, R. L., \& Taghipour, A. (2014). Skype interviewing: The new generation of online synchronous interview in qualitative research. International Journal of Qualitative Studies on Health and Well-Being, 9(1), 24152. https://doi.org/10.3402/qhw.v9.24152

Katz, D. M. (2014). The MIT school of law? A perspective on legal education in the 21st century. University of Illinois Law Review, 5, 101-142.

Katz, D. M, \& Kahn, R. L. (1966). The social psychology of organizations. John Wiley and Sons.

Laszlo, E. (1975). The meaning and significance of general system theory. Behavioral Science, 20, 9-24. https://doi.org/10.1002/bs.3830200103

LoPucki, L. M. (1996). Systems approach to law. Cornell Law Review, 82, 479-522.

McGinnis, J. O., \& Pearce, R. G. (2014). The great disruption: How machine intelligence will transform the role of lawyers in the delivery of legal services (SSRN Scholarly Paper No. ID 2436937). Social Science Research Network.

Moppett, S. A. (2013). Lawyering outside the box: Confronting the creativity crisis. Southern Illinois University Law Journal, 37, 253.

Nobles, R., \& Schiff, D. (2013). Observing law through systems theory. Hart Publishing.

Petrick, I. J., \& Martinelli, R. (2012). Driving disruptive innovation: problem finding and strategy setting in an uncertain world. Research-Technology Management, 55(6), 49.

Remus, D., \& Levy, F. S. (2015). Can robots be lawyers? Computers, lawyers, and the practice of law (SSRN Scholarly Paper No. ID 2701092). Social Science Research Network. https://doi.org/10.2139/ssrn.2701092

Ribstein, L. E. (2012). Delawyering the corporation. Wisconsin Law Review, 305-331.

Sheppard, B. (2015). Incomplete innovation and the premature disruption of legal services. Michigan State Law Review, 2015, 1797.

Simon, M., Lindsay, A. F., Sosa, L., \& Comparato, P. (2018). Lola v Skadden and the automation of the legal profession. Yale Journal of Law \& Technology, 20, 234. https://doi.org/10.1080/13600834.2015.1134144 
Simpson, B. (2016). Algorithms or advocacy: Does the legal profession have a future in a digital world? Information \& Communications Technology Law, 25, 50-61.

Susskind, R. (2013). Tomorrow's lawyers: An introduction to your future. Oxford University Press.

Susskind, R., \& Susskind, D. (2016). The future of the professions: how technology will transform the work of human experts (1st ed.). Oxford University Press.

Thompson Hine. (2017). Closing the innovation gap. https://www.thompsonhine.com

Weil, A. (2017.). 2017 Law Firms in Transition Survey. http://www.altmanweil.com/LFiT2017/

Yin, R. K. (2015). Qualitative research from start to finish (2nd ed.). Guilford.

\footnotetext{
$14 A^{7}$ The International Journal of Applied Management and Technology (IJAMT), sponsored by Walden University's College of Management and Technology, is a peer-reviewed, online journal that addresses contemporary national and international issues related to management and technology.
} 